\title{
A CRÍTICA LITERÁRIA DE ÁLVARO LINS
}

\author{
The literary criticism of Álvaro Lins
}

\section{Flávia Aparecida Hodas* \\ Universidade Estadual de Londrina}

\begin{abstract}
Resumo: Álvaro Lins foi um dos maiores nomes da crítica literária brasileira entre os decênios de 40 e 60. Atuando no jornal carioca Correio da Manhãa, entre os anos de 1941 e 1963, Lins publicou semanalmente textos críticos cuja função principal era analisar as obras de escritores estreantes e, ademais, levantar discussões pertinentes sobre temas literários. Além de tecer comentários críticos acerca das obras literárias, Álvaro Lins também publicou uma série de artigos nos quais procurava investigar o papel da própria crítica literária. Mais do que simples crítica impressionista, como viria a ser reconhecido, posteriormente, o seu trabalho, Lins entendia a crítica como uma atividade intelectual interligada a um espírito livre que se dispõe a comentar, a analisar e, sobretudo, a julgar as obras literárias. Procurando analisar os seus textos meta-críticos, o presente artigo tem por objetivo investigar a importância da crítica literária para Álvaro Lins e, principalmente, demonstrar como ele concebia o trabalho crítico em si. Em tempos tíbios, marcados por uma crítica que se despe, muitas vezes, de qualquer ato criativo e sensibilidade interpretativa, regressar ao pensamento de Lins torna-se uma espécie de manual de sobrevivência para críticos vindouros e, até mesmo, um meio de se compreender o desencantamento que envolve a crítica literária atual.
\end{abstract}

Palavras-chave: Álvaro Lins. Crítica Literária. Crítica Impressionista.

Abstract: Álvaro Lins was one of the biggest names in Brazilian literary criticism between the 40s and 60s. Working in the Correio da Manhã newspaper in Rio de Janeiro between 1941 and 1963, Lins published weekly critical texts whose main function was to analyze the works of new writers and discuss pertinent points about literary subjects. In addition to making several critical comments about literary works Alvaro Lins also published a series of articles in which he investigated the role of literary criticism. More than simple Impressionist criticism, as his work was later to be recognized, Lins understood criticism as an intellectual activity associated with free spirit that comments, analyzes and, above all, judges the literary works. In order to analyze its meta-critical texts, this article aims to investigate the importance of literary criticism for Álvaro Lins and, mainly, to demonstrate how he projected critical work. In tepid times often marked by criticism devoid of creativity and interpretive sensitivity, returning to Lins' thinking

Esta obra está licenciada sob uma Creative Commons - Atribuição 4.0

\footnotetext{
* Doutoranda em Letras pela Universidade Estadual de Londrina (UEL). Mestra em Letras pela Universidade Estadual de Londrina (UEL). Possui graduação em Letras Vernáculas (2013) e especialização em Literatura Brasileira (2015) pela Universidade Estadual de Londrina. E-mail: flaviahodas@gmail.com.
}

iD ttps://orcid.org/0000-0002-3360-2564 
becomes a kind of survival manual for future critics and the means of understanding the disenchantment surrounding current literary criticism.

Keywords: Álvaro Lins. Literary criticism. Impressionist Criticism.

Recebido em: 14/05/2018

Aprovado em: 26/08/2018

\section{Introdução}

Interpretar, sugerir e julgar, são esses os verbos que caracterizam o trabalho do crítico literário segundo Álvaro Lins. Mais do que simples texto que busca analisar uma obra literária, para Lins (2012, p. 20), a crítica literária é uma necessidade: ela "forma alicerces e levanta muros para futuras construções". Não se trata apenas de analisar uma obra, mas de desbravar caminhos de sentidos, de descobrir possibilidades interpretativas e, principalmente, de emitir juízos de valor. Para Lins, "o crítico é senão um homem que sabe ler e ensina os outros a ler (SAINTE-BEUVE, apud LINS, 2012, p. 25).

O trabalho crítico de Álvaro Lins se deu, sobretudo, entre os anos de 1941 e 1963, período em que, recém-chegado de Pernambuco, assumiu as colunas de crítica literária no jornal carioca Correio da Manhã. Conforme Eduardo César Maia (2013), nesse período, Lins exerceu uma produtiva atividade intelectual no cenário brasileiro: além de recensear novos autores, o crítico pernambucano também era responsável por proclamar a derrocada ou a ascensão da carreira de um escritor. De fato, a crítica literária de Álvaro Lins tinha o alto poder de influenciar a leitura de seus leitores e de determinar a vendagem de livros recém-publicados, como foi o caso de Sagarana, de Guimarães Rosa. Com a publicação de um texto intitulado "Uma grande estreia", Lins, ao saudar e elogiar a obra do escritor estreante, determinou um número significativo de vendas do livro e, ademais, por meio de um tom profético e auspicioso, o crítico pernambucano já proclamava a carreira brilhante que Rosa estava prestes a trilhar.

Passadas mais de cinco décadas após as produções numerosas de crítica literária de Lins, pouco, porém, pode-se resgatar de sua influência exercida nos decênios de cinquenta e sessenta. Com a ascensão das universidades, os jornais deixaram de ser os espaços privilegiados para a realização da crítica literária e, em contrapartida, o meio autorizado passou a ser os centros acadêmicos. Conforme aponta Flora Süssekind (1993), a querela travada entre a cátedra e a crítica de rodapé foi a grande responsável pela derrocada dos críticos de jornal. Para os críticos universitários, liderados pelo pensamento de Afrânio Coutinho, a crítica literária deveria ser objetiva e detentora de rigor analítico, requisitos que, para eles, não se faziam presentes dentro da crítica de rodapé. No entanto, se, por um lado, a crítica acadêmica trouxe métodos importantes para as análises das obras literárias, por outro lado, paulatinamente o seu campo de atuação foi se delimitando aos centros acadêmicos, e a influência sobre a comunidade leitora foi perdendo os seus espaços e se extinguindo a ponto de se tornar uma crítica feita somente para aqueles que habitam o universo acadêmico. Nesse sentido, talvez seja necessário regressar ao pensamento de Álvaro Lins cuja crítica literária, detentora de uma riqueza de sensibilidade 
interpretativa marcante, angariou inúmeros leitores devotos e foi potencialmente capaz de influenciar a leitura daqueles que seguiam semanalmente suas críticas de rodapé.

Entre os textos críticos que abordavam e interpretavam as obras literárias, Lins também compilou uma série de textos cuja função principal era refletir sobre os domínios da própria crítica literária, que foram selecionados por Eduardo César Maia no livro Sobre Crítica e Críticos (2012) - edição especial e comemorativa aos cem anos de nascimento do crítico pernambucano. Nesses textos meta-críticos, como é o caso de "Itinerário", "O Homem Contra as Fórmulas" e "Impressionismo e Erudição", Lins deixa claro o que entende sobre o trabalho da crítica e quais são as características principais que devem envolver o ato crítico. Diante da popularidade e renome que angariou em sua época, entender a natureza da crítica literária de Lins é mais do que mergulhar no seu próprio fazer crítico, mas, talvez, seja um meio para se compreender os próprios rumos que a crítica literária tomou nos últimos decênios. Afinal, como Álvaro Lins concebia o trabalho do crítico literário? Quais eram as formas peculiares de definilo e quais são os seus contrapontos em relação a crítica atual?

\section{O impressionismo de Álvaro Lins}

A crítica literária produzida por Álvaro Lins ficou conhecida pelo seu caráter impressionista. Marcada pela exposição de opiniões subjetivas do leitor-crítico, a crítica impressionista é caracterizada pelas impressões e experiências individuais que são suscitadas no decorrer da leitura. Em outras palavras, segundo Antonio Candido (1958, p. 1), o impressionismo é a "crítica nutrida do ponto de vista pessoal de um leitor inteligente [...] é a crítica por excelência e pode ser considerada [...] a aventura do espírito entre os livros. Se for eficaz, estará assegurada a ligação entre a obra e o leitor, a literatura e a vida quotidiana". Entre o rol de críticos que se apossaram de um método impressionista, pode-se citar os nomes de Virginia Woolf, Anatole France e dos críticos brasileiros Álvaro Lins e Sérgio Milliet, os quais deixavam entrever em seus textos críticos os revérberos que as obras literárias provocaram em suas leituras.

Acompanhando a subjetividade e as impressões levantadas no decorrer da leitura, a crítica impressionista também se caracteriza por um posicionamento erudito e humanista do crítico. O humanismo, que se constitui de um termo de difícil conceituação, pois assumiu, no decorrer dos séculos, diferentes acepções, pode ser definido como uma corrente filosófica e, até mesmo, como uma postura que se preocupa com temas interligados à condição humana. Em outras palavras, a crítica detentora um de viés humanista tende a analisar a obra enquanto uma forma de conhecimento que torna a experiência humana concreta dizível e inteligível:

O que caracteriza, pois, os críticos da linhagem humanista é a posse de um espírito erudito, inclinado à investigação, típico dos humanistas mais eminentes. Para eles, o fenômeno literário é de natureza filosófica, e a literatura, um instrumento de conhecimento do homem. A noção de estilo deixa de ser gramatical para se tornar filológica (MARTINS apud MAIA, 2013, p. 17). 
Nesse sentido, a crítica literária impressionista, ao dialogar com uma perspectiva humanista, não busca analisar intransitivamente a obra, isto é, a obra literária não é um produto fechado em si mesmo, mas busca entrevê-la como uma forma que estabelece um permanente diálogo com a experiência e condição humanas. Dentro dessa perspectiva, a crítica não seria um arcabouço de fórmulas a fim de desvendar a estrutura dos textos literários, como postulavam os adeptos do formalismo russo e do estruturalismo francês, mas, muito mais além, uma forma de apresentar as vivências humanas.

É importante analisar que a crítica impressionista não se configura como um conceito de definição unívoca, mas uma crítica que se situa em um amplo território de possibilidades. Dialogando por vezes com outras áreas do conhecimento humano, como Filosofia, História e outras áreas do saber, a crítica impressionista tampouco se constitui de um modelo cujas leis e regras são estigmatizadas, mas de um uma prática cujos os contornos não são bem delimitados, o que possibilita ao crítico, portanto, uma gama de caminhos diversos para análise das obras literárias. Entretanto, a partir de seus textos críticos e meta-críticos, constata-se que a crítica de Álvaro Lins não se limitava a um diletantismo ou, até mesmo, a um impressionismo puro. No seu artigo "Impressionismo e Erudição", publicado em 1941, embora teça uma série de comentários sobre o fazer crítico do escritor português Fidelino de Figueiredo, Lins expõe como concebe o seu próprio modelo de crítica literária. Ao contrário de uma crítica que viva em função da expressão subjetiva e das experiências hedonistas originadas no decorrer da leitura, Álvaro Lins observa o seu próprio trabalho crítico como uma fusão entre o posicionamento subjetivo, portanto, impressionista, e uma perspectiva objetiva, próximo a uma análise mais tecnicista.

Em vários de seus artigos, como é o caso de "Crise e possibilidade da poesia" (1963), além de expressar suas opiniões pessoais, Lins também revela um grande domínio de conhecimentos especializados acerca da própria estrutura das obras literárias. Nessa crítica em específico, ao analisar os poemas de Drummond e de Américo Facó, Lins interpreta-os a partir de suas métricas, sistemas rítmicos, figuras de linguagem e uma infinidade de outros termos técnicos que revelam, em última instância, não somente uma crítica diletante, mas também uma crítica detentora de uma objetividade analítica. Dito de outro modo, além de expressar suas opiniões pessoais sobre uma obra literária, Lins enxergava a crítica como um trabalho objetivo, que requer conhecimento especializados sobre a obra literária. É na confluência entre a subjetividade e a técnica que se erige o trabalho crítico de Lins, pois "sobre ela é que se ergue a crítica criadora, livre nos seus movimentos de espírito, mas apoiada e impulsionada pela ciência literária" (LINS, 2012, p. 50).

É importante analisar que a literatura, para Lins, não se trata somente de uma produção artística, mas, em contrapartida, trata-se de um tipo de "gnose". (LINS, 2012, p. 51) Em outras palavras, a literatura é uma forma de conhecimento humano, "um conhecimento do homem através do espírito, [...] rigorosamente, a literatura é uma forma de conhecimento da realidade" (LINS, 2012, p. 51). Realidade essa concebida por Lins como a junção de três aspectos: a realidade do homem, do universo e de Deus. Assim, a crítica literária não pode ser apenas 
pensada como uma análise em que os pensamentos subjetivos se esvaem por suas linhas ou o rigor das análises buscam decompor o sistema orgânico das formas literárias, porém como uma forma de conhecimento que, ao atrelar-se às obras literárias, também revela conhecimentos sobre o próprio homem. Tratando-se de uma gnose, isto é, de uma forma de conhecimento, tal como a própria literatura, a crítica exige muito mais do que a simples exposição de impressões:

Sabemos que a crítica não é só impressionismo, não é só apreciação ou julgamento no plano subjetivo. Não é somente uma arte. Por outro lado, porém, ela não pode se fechar aos limites de um seco objetivismo, não pode ser uma prisioneira das leis e dos conceitos de outras ciências. A crítica se forma de uma união mais complexa de elementos objetivos e subjetivos. Existe necessariamente uma ciência da literatura que exige conhecimentos especializados e metodologia própria. [...] O verdadeiro crítico há de ser um erudito e um impressionista; esta síntese é que faz da crítica uma obra criadora dentro da literatura. [...] o escritor crítico é um criador de ideias. (LINS, 2012, p. 50)

Embora Lins seja reconhecido como um dos críticos impressionistas mais importantes da literatura brasileira, o seu modelo crítico assume nuanças singulares, as quais vão além de um mero esforço subjetivista. Elaborando uma crítica que coadune as opiniões pessoais aos traços de objetivismo, a crítica literária de Lins busca ser, antes de mais nada, um espaço aberto a possibilidades e livre de qualquer fórmula pronta. Não se trata apenas de criar textos críticos que busquem salientar as expressões do autor, tampouco se trata de análises rigorosas, repletas de termos técnicos e que tendem a fornecer uma análise científica sobre a obra literária. $\mathrm{O}$ trabalho crítico, segundo o pensamento de Álvaro Lins, é uma confluência entre a subjetividade e objetividade, o que possibilita, portanto, a aventura interpretativa por meio de um espírito que desejar ser, acima de tudo, livre para criar.

\section{Álvaro Lins e o trabalho crítico}

Diante de uma época em que a crítica universitária se fazia cada vez mais presente e arraigada na sociedade brasileira, Álvaro Lins surgiu e se afirmou como uma voz contrária ao discurso vigente. A crítica literária, após a década de 1950, paulatinamente, concentrou-se nos centros acadêmicos, cedendo, cada vez mais, às exigências e às regras do campo científico. Lins travou longos debates com Afrânio Coutinho, crítico que, recém-chegado dos Estados Unidos e influenciado pelo New Criticism, exerceu grande influência para a mudança de paradigmas da crítica literária feita no Brasil até então. Se, conforme aponta Süssekind (1993, p.16-17), “o poder literário era em parte sinônimo de uma presença constante nas páginas e no noticiário de jornal", as universidades, por outro lado, "quebraram a antiga hierarquia, ligado ao prestigio político das profissões liberais". A célebre polêmica estabelecida entre a cátedra e a crítica de rodapé, justamente representados por Afrânio Coutinho e Álvaro Lins respectivamente, foi responsável pela derrocada da crítica literária realizada nos meios jornalísticos. Contudo, diante dos seus inúmeros trabalhos publicados, os quais não se limitavam ao campo jornalístico, mas abarcavam publicações em livros (A técnica do romance em Marcel Proust (1956), O relógio 
e o quadrante (1964), O romance brasileiro contemporâneo (1967), Poesia moderna no Brasil (1968) etc.) e, dada a influência exercida no campo intelectual de sua época, estudar a concepção de Álvaro Lins sobre o próprio trabalho crítico é mais do que mergulhar apenas em um campo de definições possíveis, mas, talvez, um meio de conceber, nos momentos atuais, uma espécie de manual de sobrevivência para os críticos vindouros.

Apesar de ser reconhecido pelos seus textos críticos sobre obras e autores, Lins compilou uma série de textos cuja função principal era refletir sobre o próprio trabalho da crítica literária. Longe de formular quaisquer tipos de regras ou esquemas a serem seguidos, o crítico pernambucano apresentou vários princípios que deveriam guiar o trabalho do crítico. Em um dos seus textos mais conhecidos, intitulado "Itinerário", primeiro texto publicado no jornal Correio da Manhã, em 1940, Lins apresenta uma espécie de "profissão de fé" de seu próprio ofício enquanto crítico literário. Nesse texto, ele deixa claro que o trabalho do crítico deve ser guiado por três princípios fundamentais: o princípio da individualidade, da personalidade e da liberdade.

Opondo-se claramente a um suposto pensamento de rebanho e a alguns preceitos sociais que se enraizavam e dominavam o pensamento de uma época, conforme aponta Eduardo César Maia (2013), Lins tinha um verdadeiro horror às ideias coletivas, pois estas eram concebidas como fruto de um espírito pobre e, consequentemente, escravo. Esquivando-se de modelos prontos e de qualquer princípio ideológico, para Lins, a crítica deve ser, antes de mais nada, uma prática que preze pela liberdade individual do crítico. Se a própria literatura se constitui de um campo aberto e livre a constantes experimentações, a crítica literária, seguindo os mesmos caminhos, não pode se limitar a modelos fixos, tampouco a regras estratificadas. Nas palavras do crítico:

a obra de arte não fica sendo, apenas, um 'produto', um 'trabalho', uma
'tarefa'. É tudo isso e muito mais: revela-se como uma expressão mesma da
vida pessoal e universal. Revela-se uma maneira mesma, e a mais alta, de
viver, de existir, de se realizar humanamente, como imagem e semelhança de
Deus [...] Pois o que se conclui é que a verdade da arte não se encontra toda
no subjetivismo ou no objetivismo; na forma ou na ideia; na prosa ou na
poesia; no classicismo ou no simbolismo. Mas se encontra no objetivismo e
no subjetivismo, na forma e na ideia, na prosa e no verso; no classicismo e no
simbolismo. (LINS, 2012, p. 39)

Ao caracterizar a crítica literária como um espaço livre e aberto à confluência de perspectivas, a individualidade se torna um dos requisitos principais para o fazer crítico. Segundo Lins (2012, p. 26), "para saber ler e para ensinar os outros a ler - o crítico há de ser um solitário, porque somente na solidão o homem conquista a liberdade nos seus estados de absoluta pureza e de absoluta força. Diferentemente da esfera política e econômica que, conforme Lins, será mais forte quanto maior for o número de seus integrantes, na literatura, em contrapartida, a realização artística se dá somente na individualidade. O crítico deve desfrutar, nesse sentido, de sua própria solidão e da sua própria individualidade, pois é somente nesse estado que se erige uma arte verdadeiramente criadora. Nas palavras do crítico, a solidão é a 
causa e consequência da criação artística: "porque é um solitário é que o artista constrói um universo de imagem onde possa introduzir as raízes mesmas do seu ser. Porque é um artista é que um homem tem que ser solitário, porque somente na solidão a arte existe" (LINS, 2012, p. 26).

Juntamente a essas características, Lins afirmava que a crítica literária deveria estar isenta de qualquer fator ideológico ou de qualquer tipo de sectarismo. Em uma época em que se tornava cada vez mais frequente a defesa de bandeiras ideológicas dentro da literatura e da crítica literária, o crítico pernambucano opunha-se a essa postura que buscava priorizar o hasteamento de bandeiras ideológicas, em vez de destacar os valores estéticos e literários da obra. O crítico, antes de mais nada, deve recusar qualquer ideologia como pretexto para a análise das obras literárias e, de outro modo, o único partido que o crítico pode assumir é o partido da própria literatura:

Tanto se tem falado ultimamente de arte popular, de arte interessada, de arte social, que já é tempo de se estabelecer uma reação em favor da arte pura, da arte desinteressada, da criação como expressão pessoal. Não se trata de anular o 'social', mas de colocá-lo na sua posição, que é abaixo do 'pessoal'. Fazer o contrário é prestar-se ao jogo dos regimes da arte escreva: o jogo dos nazistas e dos comunistas. Durkheim, que se pretendia homem da ciência pura e não um político, fez ingenuamente este jogo, com a sua obsessão do 'social' acima de tudo. A Europa dos nossos dias está mostrando até onde vai chegar este predomínio do social - quer ele seja de Durkheim ou de Marx ou de Rosemberg. (LINS, 2012, p. 25)

Diante da liberdade e da individualidade, o crítico literário deve buscar pela permanente autoafirmação de sua personalidade em detrimento de se sujeitar a qualquer tipo de escravidão ideológica. Ao tomar o partido da literatura, o crítico deve expor, principalmente, as suas próprias opiniões, emitir os seus juízos de valor, pois todo trabalho crítico se constitui de um tríplice aspecto: "interpretação, sugestão e julgamento" (LINS, 2012, p. 21). Nesse sentido, é preciso que o sujeito crítico, em vez de se esconder por trás de linguagens impessoais e de se acomodar a um modelo único de análise, exponha e emita as suas opiniões pessoais. Nas palavras de Lins (2012, p. 36), "as obras estéticas que nos transmitem uma sensação mais pura e mais íntima de vida são aquelas que nasceram dos espíritos livres: livres das escolas, das fórmulas, dos preconceitos, de todos os limites e de todas as servidões". É somente por meio de uma personalidade livre e sincera, portanto, que a crítica será capaz de impactar o público leitor.

A crítica literária se torna, assim, um espaço aberto para a criação do indivíduo. É importante observar que uma das polêmicas que acompanha a crítica literária, no decurso dos séculos, é justamente a relação que ela estabelece com a própria literatura. Ora se afirmando como matéria subordinada à obra literária, ora como independente, esse debate, ao longo dos séculos, gerou inúmeras incertezas e, até mesmo, um ranço por parte de inúmeros críticos literários que viam seus artigos como simples textos auxiliares à compreensão da obra literária. O trabalho crítico não é apenas um mero texto que se sujeita a uma obra literária, porém é 
também um trabalho de criação. Quando se exige que um crítico seja um criador, não se exige que ele componha poemas ou romances, mas dentro de todo o trabalho crítico também existe um lado criador: "a criação do crítico lhe vem da possibilidade de levantar, ao lado ou além das obras dos outros, ideias novas, direções insuspeitadas, novos elementos literários e estéticos, sugestões de bom gosto, sistematizações, esquematizações, quadros de valores" (LINS, 2012, p. 20). Além disso, Lins não concebia a crítica literária como matéria inferior à literatura, mas como fenômenos intimamente interligados e interdependentes. Afinal, no decurso da história literária, grande parte das obras e autores só foram perpetuados e consagrados a partir das interpretações positivas e favoráveis realizadas por críticos literários.

Enquanto a literatura apresenta-se como um fenômeno que busca imitar ou, até mesmo, retratar aspectos da realidade e a da vida humana, a crítica literária serve como uma espécie de preceptora dessas experiências. Ou seja, a crítica torna-se uma consciência sobre a obra literária:

A crítica representa para a literatura o mesmo fenômeno de interpretação, de conhecimento, de consciência que a literatura representa para a vida. A crítica é uma consciência do fenômeno literário do mesmo modo que a literatura é uma consciência do fenômeno vital. Ao contato da natureza física ou humana, a literatura toma as formas mais propícias para a sua expressão; ao contato da obra literária, do seu criador, ou das ideias puras, a crítica toma também as formas mais próprias para a sua interpretação e julgamento. (LINS, 2012, p. 123)

Interpretação, sugestão, julgamento, autoafirmação da personalidade, liberdade e individualidade são as características principais que devem envolver o trabalho crítico, segundo Álvaro Lins. É importante salientar que, de acordo com Lins, os julgamentos também devem ser imunes a qualquer resquício de sectarismo ou elogios exacerbados. $\mathrm{O}$ ato de julgar uma obra não deve nascer de nenhum um elo sentimental, mas de análises que funcionem como interpretações justas e verdadeiras sobre a obra literária. O trabalho do crítico é situar a obra literária dentro de um arcabouço valorativo mais amplo, é identificar os seus valores intrínsecos e "orientar o público para o seu verdadeiro gosto e para a sua verdadeira finalidade no caminho da arte" (LINS, 2012, p. 25). A crítica torna-se, nesse sentido, um fator indispensável para que as obras sejam identificadas como obras de valor e que o seu valor seja perpetuado no decorrer dos séculos. Assim, a crítica

tem duas faces: a interpretação e o julgamento. Interpretação deve-se entender como a sua fonte criadora, como a força poética que existe em todas as atividades literárias: é a compreensão, e a penetração, é a análise é a reconstituição, é a revelação, é o senso psicológico, é o poder sugestivo, é o jogo e o debate de ideias. [...] Para o julgamento, ao contrário, a faculdade dominante será a razão. Aí estão os dois graus da crítica. Enquanto a interpretação é a sua fonte criadora, o julgamento é a justificação da sua existência dentro do fenômeno literário. (LINS, 2012, p. 117-118)

Em meio a uma época em que a crítica literária se tornou "cinzenta", como aponta Paulo Franchetti (2006), despida de julgamentos pessoais, de impressões subjetivas e das experiências 
individuais que as leituras provocam, muito há que se aprender com a forma pela qual Álvaro Lins conduzia o seu trabalho crítico. Ao interpretar e julgar, sempre diante de uma postura envolvente, questionadora e, sobretudo, perquiridora em relação ao objeto literário, a crítica assume o poder de desbravar caminhos de sentido e a capacidade de compartilhar experiências de leitura. Afinal, "como definir um livro que nos transmite uma impressão profunda, um conhecimento definido, uma consciência sensível, de alguma coisa que antes nos era desconhecida" (LINS, 2012, p.125-126), a não ser por meio de uma crítica sincera e criativa? A crítica, longe de ser apenas um trabalho anatômico sobre a obra, é, antes de tudo, um aporte de compreensão para o leitor, além de ser uma ferramenta que colabora para a fruição da obra artística. Ela não se limita a modelos estratificados, mas flui de acordo com cada obra literária. O crítico literário, para Álvaro Lins, é, em suma, aquele sujeito que, de certa forma engajado com a cultura literária, aperfeiçoou a sua capacidade interpretativa a partir de inúmeras leituras. É o homem que, enquanto sujeito erudito, tem um alcance sobre os seus leitores e que, ao saber ler, também é um sujeito potencialmente capaz de ensinar os outros a ler.

\section{Considerações finais}

Com a ascensão das universidades, um tipo de crítica pautada em formas e padrões científicos alastrou-se pelo cenário cultural brasileiro. A crítica realizada em jornais, que tinha o poder de influenciar a leitura dos seus seguidores e, até mesmo, funcionar como uma espécie de campo aberto ao compartilhamento de experiências literárias, foi tornando-se cada vez mais ínfima. Obviamente, os tempos são outros e o público não se dispõe apenas da literatura para se entreter, (in)formar e, até mesmo, para adquirir conhecimentos interligados a própria vida humana. Além disso, também não se pode questionar que os requisitos solicitados pelas academias são outros e diversos daqueles que se instauravam nos meios jornalísticos. No entanto, talvez, falte dentro da cultura brasileira atual a imagem de um crítico literário como a de Álvaro Lins.

Como aponta Paulo Franchetti (2006, p. 51), hoje "parece que está ausente da quase totalidade dos textos mais recentes a exposição das razões do crítico num discurso que traga a primeiro plano a sua reação imediata de leitura". De fato, a objetividade analítica, a afiliação a determinadas correntes de pensamento, se não exclui de todo, pelo menos coloca de lado grande parte da subjetividade e da experiência única em face do objeto literário. Ao lado da crítica acadêmica, sistemática e objetiva, é preciso que se resgate uma crítica literária mais livre e mais disposta a mergulhos subjetivos e que, conforme Álvaro Lins, exponha o gosto, a sensibilidade interpretativa e a própria subjetividade do crítico literário.

\section{Referências}

CANDIDO, Antonio. Crítica impressionista. 1958. Disponível em: < https://periodicos.sbu.unicamp.br/ojs/index.php/remate/article/viewFile/8635988/3697> Acesso em: 14/05/2018. 
FRANCHETTI, Paulo. Crítica e saber universitário. In: SANTOS, Alcides Cardoso (Org.). Estados da crítica. Curitiba: Editora UFPR, 2006. p. 47-62.

LINS, Álvaro. A técnica do romance em Marcel Proust. Rio de Janeiro: José Olympio, 1956. Crise e possibilidade da poesia. In: . Jornal de crítica. Rio de Janeiro: José Olympio, 1963. 7. série. . O relógio e o quadrante. Rio de Janeiro: Civilização Brasileira, 1964. . O romance brasileiro contemporâneo. Rio de Janeiro: Edições de Ouro, 1967. . Poesia moderna no Brasil. Rio de Janeiro: Edições de Ouro, 1968.

. Sobre crítica e críticos: ensaios escolhidos sobre literatura e crítica literária, com algumas notas de um diário de crítica. Organização de Eduardo César Maia e apresentação de Lourival Holanda. Recife: Cepe, 2012.

MAIA, Eduardo Cesar. Crítica e contingência: uma reavaliação da crítica humanista através do perspectivismo filosófico de José Ortega e Gasset e do personalismo crítico de Álvaro Lins. 2013. $237 \mathrm{f}$. Tese (Doutorado em Letras na Área de Teoria da Literatura) - Universidade Federal de Pernambuco, Recife, 2013.

SÜSSEKIND, Flora. Rodapés, tratados e ensaios: a formação da crítica brasileira moderna. In: . Papéis colados. Rio de Janeiro: UFRS, 1993. p. 13-33.

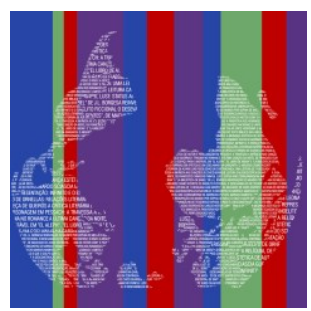

